\title{
Quantitative NH measurements by using laser-based diagnostics in low-pressure flames
}

\section{Nathalie Lamoureux*, Laurent Gasnot, Pascale Desgroux}

\author{
Affiliation \\ Univ. Lille, CNRS, UMR 8522 - PC2A - Physicochimie des Processus de Combustion et de l'Atmosphère, F- \\ 59000 Lille, France
}

\section{Corresponding author:}

lab. PC2A, bat. C11, Cité scientifique, 59655 Villeneuve d'ascq, France, nathalie.lamoureux@univ-lille1.fr,

\section{Colloquium: III.}

Total: 6174 words (method 1)

Main text: 3675 words

References: $(27+2) * 2.3 * 7.6: 507$ words

2 Equations: $(4+3) * 7.6: 53$ words

Table $1(6+2) * 7.6 * 6: 364$ words

Table $2(7+2) * 7.6 * 6: 410$ words

Table $3(6+2) * 7.6 * 5: 304$ words

Fig. 1. $(46.9+10) * 2.2+58: 183$ words

Fig. 2. $(54.7+10) * 2.2+14: 156$ words

Fig. 3. $(52.8+10) * 2.2+24: 162$ words

Fig. 4. $(63.3+10) * 2.2 * 2+38: 360$ words

SMM.pdf as Supplementary Materials 


\begin{abstract}
(252 words)
$\mathrm{NH}$ is a key short-lived radical involved in the prompt-NO formation. Quantification of $\mathrm{NH}$ is thus particularly important for testing the NO kinetic mechanisms. However, quantitative measurements of native $\mathrm{NH}$ in hydrocarbon/oxygen/nitrogen flames remain very scarce. Therefore, in this work, the mole fractions of native $\mathrm{NH}$ were obtained using a combination of laser-based diagnostics; Laser Induced Fluorescence (LIF) and Cavity Ring-Down Spectroscopy (CRDS). The NH species was probed after exciting the transition $R_{1}(6)$ in the $A^{3} \Pi-X^{3} \Sigma^{-}(0-0)$ system at $333.9 \mathrm{~nm}$. The mole fraction profiles of $\mathrm{NH}$ were successfully obtained in premixed low-pressure flames of $\mathrm{CH}_{4} / \mathrm{O}_{2} / \mathrm{N}_{2}$ and $\mathrm{C}_{2} \mathrm{H}_{2} / \mathrm{O}_{2} / \mathrm{N}_{2}$ at two equivalence ratios of 1.00 and 1.25 . The estimated detection limit for the $\mathrm{NH}$ radical was around $4.5 \times 10^{8}$ molecule $\mathrm{cm}^{-3}$ (i.e. $2 \mathrm{ppb}$ in mole fraction at $1600 \mathrm{~K}$ ), which is nearly 2 orders of magnitude lower than previous values reported in the literature. These new experimental results were compared with predictions by a recently developed NO model (namely NOMecha2.0). In the case of the $\mathrm{CH}_{4}$ flames, a satisfying agreement between the experiment and model was observed. However, in the case of the $\mathrm{C}_{2} \mathrm{H}_{2}$ flames, some discrepancies were observed. Model analysis has highlighted the importance of the HCCO radicals in the NH formation through the $\mathrm{HCNO} \rightarrow \mathrm{HNCO} \rightarrow \mathrm{NH}_{2}$ reactions pathway. Modification of the rate constant values of the reactions $\mathrm{C}_{2} \mathrm{H}_{2}+\mathrm{O}$ and $\mathrm{HCCO}+\mathrm{O}_{2}$, which are key reactions for both the acetylene laminar flame speed and the $\mathrm{HCCO}$ predictions, has enabled the model to satisfactorily predict the experimental $\mathrm{NH}$ and NO profiles also in the $\mathrm{C}_{2} \mathrm{H}_{2}$ flames.
\end{abstract}

\title{
Keywords:
}

NH; CRDS; LIF; low-pressure flame; prompt-NO 


\section{Introduction}

The NH radicals, which are important intermediate species in the NO formation process, have been measured in the past using laser-based diagnostics in flames. Relative $\mathrm{NH}$ species profiles were obtained in premixed flames by using Laser Induced Fluorescence (LIF) since the 80-90's [1-6]. Measurements were exclusively performed in mixtures seeded with $\mathrm{N}$-containing species $\left(\mathrm{NO}, \mathrm{NO}_{2}\right.$, $\mathrm{N}_{2} \mathrm{O}, \mathrm{NH}_{3}$ ) that allow increasing the $\mathrm{NH}$ quantity. The LIF measurements were performed either in the $\mathrm{A}^{3} \Pi-\mathrm{X}^{3} \Sigma^{-}(0-0)$ vibrational band of NH around $336 \mathrm{~nm}$ or in the (1-0) vibrational band around $303 \mathrm{~nm}$. Relative LIF measurements were calibrated using absorption methods [1,3,4]. The detection limit was found to be around $1 \mathrm{ppm}$. Brackmann et al. [6] measured $\mathrm{NH}$ profiles in atmospheric $\mathrm{NH}_{3} /$ air flames by using saturated LIF. The NH-LIF signal was calibrated in mole fraction by using a bidirectional LIF method applied to $\mathrm{OH}$ with an overall uncertainty estimated to be $40 \%$ and a detection limit of $2 \times 10^{13}$ molecule $\mathrm{cm}^{-3}$. Derzy et al. [7] measured mole fraction profiles of $\mathrm{NH}$ using Cavity RingDown Spectroscopy (CRDS) in low-pressure $\mathrm{CH}_{4} /$ air flames seeded with $1.7 \%$ of $\mathrm{N}_{2} \mathrm{O}$. They estimated the detection limit for measuring $\mathrm{NH}$ to be $4 \times 10^{10}$ molecule $\mathrm{cm}^{-3}$ probing the $\mathrm{R}_{1}(6)$ transition at $333.9 \mathrm{~nm}$. To the best of our knowledge, native NH has been measured only once in atmospheric

$\mathrm{CH}_{4} /$ air flames by using saturated LIF [8]. The LIF signal was calibrated into mole fraction by Rayleigh scattering with a value as low as $0.3 \mathrm{ppm}$ (i.e. $10^{12}$ molecule $\mathrm{cm}^{-3}$ ) and an overall uncertainty estimated at about $40 \%$.

In our laboratory, we have previously shown the strong complementarities of LIF and CRDS to quantify trace species in premixed flames provided that they fluoresce. The LIF/CRDS coupling already allowed measuring species with mole fractions as low as a few ppb in the case of NCO [9].

In the continuation of our previous works carried out for the prompt-NO formation in premixed low-pressure flames [10], the present paper reports quantitative measurements of native NH by using LIF and CRDS techniques for the first time. LIF profiles of NH were measured in five lowpressure flames by probing the $\mathrm{R}_{1}(6)$ transition at $333.9 \mathrm{~nm}$. The absorption oscillator line strength was calculated with the PGOPHER program [11]. LIF profiles of $\mathrm{NH}$ were converted into mole 
fraction profiles by using the integrated spectral absorptivity obtained by CRDS in a flame seeded with $2.2 \%$ of $\mathrm{N}_{2} \mathrm{O}$. The LIF detection limit is significantly improved in the present work by optimizing the collection volume and the LIF signal processing. The experimental NH profiles were compared to those simulated using the NOMecha2.0 submechanism which has been recently validated for the prompt-NO formation [10]. NOMecha2.0 is associated either to a methane mechanism [12] or to a acetylene mechanism [13].

\section{Experimental setup}

\subsection{Low-pressure burner and gas supply}

Experiments were undertaken in laminar $\mathrm{CH}_{4} / \mathrm{O}_{2} / \mathrm{N}_{2}$ or $\mathrm{C}_{2} \mathrm{H}_{2} / \mathrm{O}_{2} / \mathrm{N}_{2}$ premixed flames stabilized at $5.33 \pm 0.01 \mathrm{kPa}$ (40 Torr) on a 6-cm diameter bronze water-cooled McKenna burner. Regulation of the pressure is achieved within $\pm 0.3 \%$ by using an automatic valve (Oerlikon CMOVE/MOVE1250). The burner is mobile in translation in the vertical axis allowing measuring species profiles as function of the height above the burner (HAB). Details about the burner and the gas supply were given in $[14,15]$. Additionally, a $\mathrm{N}_{2} \mathrm{O}$-doped flame (named $\mathrm{CH} 4-\mathrm{N} 2 \mathrm{O}$ ) was stabilized in order to calibrate relative concentration of $\mathrm{NH}$ species in mole fraction by CRDS. Flame compositions and volumetric gas flow rates are reported in Table 1 . These flame conditions, identical to those previously studied in the laboratory, were used to validate NOMecha2.0 [10]. The temperature profiles were previously obtained by LIF thermometry according to a procedure described in [14]. They are reported in [10], except for flame $\mathrm{CH} 4-\mathrm{N} 2 \mathrm{O}$ in which the temperature was measured equal to $1790 \mathrm{~K}$ at $\mathrm{HAB}=5.75 \mathrm{~mm}$ [9].

Table 1. Flame compositions. Gas flow rates are reported in slpm (standard refers to $0^{\circ} \mathrm{C}$ and atmospheric pressure). $\phi$ is the equivalence ratio. 


\begin{tabular}{|c|c|c|c|c|c|}
\hline Flame & fuel & $\mathrm{O}_{2}$ & $\mathrm{~N}_{2}$ & $\mathrm{~N}_{2} \mathrm{O}$ & $\phi$ \\
\hline $\mathrm{CH} 4(100)$ & $0.48 \pm 0.01$ & $0.96 \pm 0.02$ & $3.35 \pm 0.05$ & - & 1.00 \\
\hline $\mathrm{CH} 4(125)$ & $0.60 \pm 0.01$ & $0.96 \pm 0.02$ & $3.29 \pm 0.05$ & - & 1.25 \\
\hline $\mathrm{C} 2 \mathrm{H} 2(100)$ & $0.53 \pm 0.01$ & $1.06 \pm 0.02$ & $4.84 \pm 0.05$ & - & 1.00 \\
\hline $\mathrm{C} 2 \mathrm{H} 2(125)$ & $0.42 \pm 0.01$ & $1.06 \pm 0.02$ & $4.84 \pm 0.05$ & - & 1.25 \\
\hline $\mathrm{CH} 4-\mathrm{N} 2 \mathrm{O}$ & $0.48 \pm 0.01$ & $0.91 \pm 0.02$ & $3.04 \pm 0.05$ & $0.10 \pm 0.01$ & 1.00 \\
\hline
\end{tabular}

\subsection{Laser set-up}

The pulsed laser system consists of a frequency-doubled Nd:YAG laser (Powerlite DLS8000, Continuum) pumping a dye laser (ND6000, Continuum). Wavelengths around $335 \mathrm{~nm}$ with a spectral bandwidth of $0.3 \mathrm{~cm}^{-1}$ were provided by doubling the fundamental dye radiation of a mixture (LDS698+DCM) diluted in methanol.

LIF and CRDS signals were collected by a photomultiplier tube (PMT) (XP2020Q, Photonis) and recorded on a digital oscilloscope (Lecroy HDO4000, 12-bit vertical resolution, 1GHz bandwidth, 1.25 GS/s). During spectrum acquisition, the laser wavelength was scanned at a rate equal to $0.25 \mathrm{pm}$ $\mathrm{s}^{-1}$ and the signal was averaged over 10 laser shots. For species profiles measurements, the signal was averaged over 300 laser pulses. Signals from the oscilloscope and the dye laser wavelength were transferred in real time on a PC, and treated with Labview programs.

\subsubsection{LIF}

The laser beam was introduced unfocused parallel to the burner surface and shaped using a horizontal slit of $300 \mu \mathrm{m}$ height and $2 \mathrm{~mm}$ width in front of the burner. The LIF signal was collected at $f / 4$ by a two-lenses system and focused on the entrance slit of a $0.275 \mathrm{~m}$ monochromator. The entrance slit ( $200 \mu \mathrm{m}$ width, $10 \mathrm{~mm}$ height) was parallel to the laser axis. The collection volume is estimated to be equal to $4 \mathrm{~mm}^{3}$. The output slit was adjusted to obtain the desired collection bandwidth. For measurements performed in the $\mathrm{C}_{2} \mathrm{H}_{2} / \mathrm{O}_{2} / \mathrm{N}_{2}$ flames, the PMT saturation due to the strong flame emission at $338 \mathrm{~nm}$ was avoided by the use of a fast electronic shutter (Oriel fast shutter 76994/76995) placed in front of the monochromator. The shutter opening (with a gate of $13 \mathrm{~ms}$ ) was synchronized with the laser Q-switch signal and delayed appropriately in order to collect the fluorescence signal. The prompt-LIF signal is measured at the peak value of the temporal LIF signal, limiting the effect of 
possible quenching variations. It allows measuring the relative population of the species in the rotational level J", $\mathrm{N}_{\mathrm{J}}$.

\subsubsection{CRDS}

CRDS measurements for $\mathrm{NH}$ were performed by using an experimental set-up and data processing similar to the one described for $\mathrm{CH}$ measurements in [14,15]. The $420 \mathrm{~mm}$ length cavity is ended by two highly reflective mirrors (LaserOptik, $25 \mathrm{~mm}$ diameter, $250 \mathrm{~mm}$ radius of curvature, reflectivity>0.997). The laser beam was shaped with a system consisting of a $100 \mu \mathrm{m}$ pinhole aperture and two lenses (100 and $175 \mathrm{~mm}$ focal lengths) in order to match approximately the $\mathrm{TEM}_{00}$ transverse mode of the optical cavity. The CRD signal was collected by the PMT in front of which was placed a UG11 filter. Cavity decaytimes were determined from an exponential fitting over $1.6 \mu$ s. The ringdown decaytime in the burned gases (in absence of $\mathrm{NH}$ absorption) was typically equal to $475 \mathrm{~ns}$. The concentration of the absorbing species is determined from the measurement of the decaytime on- and off-resonance with the transition as detailed in $[16,17]$. The off-resonance wavelength was selected by detuning the laser by $30 \mathrm{pm}$ from the on-resonance one.

\section{NH spectroscopy}

The PGOPHER program (version 9.1.100) [11] allows calculating the absorption spectrum in absolute intensity, and also extracting the rotational terms of energy $\left(\mathrm{E}_{\mathrm{J}^{\prime}}\right)$, the rotational Einstein A coefficients $\left(A_{J^{\prime} J^{\prime \prime}}\right)$, or the rotational oscillator strength $\left(f_{J^{\prime \prime} J}\right)$. The revised spectroscopic constant values of $\mathrm{NH}$ in the $\mathrm{A}^{3} \Pi-\mathrm{X}^{3} \Sigma^{-}$system proposed by Ram and Bernath [18] were introduced in PGOPHER. The vibrational and rotational partition functions in the ground state $X^{3} \Sigma^{-}$were calculated by using the equilibrium molecular constants reported by Brooke et al. [19]. The Boltzmann factors were determined as function of the temperature by using $E_{\mathrm{J}}$, calculated by PGOPHER.

In order to calculate the values of $A_{J^{\prime} J^{\prime}}$ and $f_{J^{\prime \prime} J^{\prime}}$, the electronic transition moment $\left(\sqrt{q_{v^{\prime} v^{\prime \prime}}} R_{e}\right)$ that is required, was calculated (in D) from the vibronic Einstein A coefficient $\left(A_{v^{\prime} v^{\prime \prime}}\right.$ in unit $\left.\mathrm{s}^{-1}\right)$ according to Eq. (1) derived from Larsson [20]: 


$$
q_{v \prime v^{\prime \prime}} R_{e}^{2}=3.1895 \times 10^{6} \frac{1}{\bar{v}^{3}} \frac{2-\delta_{0, \Lambda^{\prime}}}{2-\delta_{0, \Lambda^{\prime}+\Lambda^{\prime \prime}}} A_{v \prime v^{\prime \prime}}
$$

where $\bar{v}$ is the center wavenumber of the $\left(v^{\prime} v^{\prime \prime}\right)$ transition in $\mathrm{cm}^{-1}$. For a $\Pi \rightarrow \Sigma$ transition, the ratio (2$\left.\delta_{0, \Lambda^{\prime}}\right) /\left(2-\delta_{0, \Lambda^{\prime}+\Lambda^{\prime \prime}}\right)($ where $\delta$ is the Kronecker delta) is equal to one [20].

According to the Einstein A coefficient values newly determined by Fernando et al. [21], $\left(\mathrm{A}_{00}=2.54 \times 10^{6} \mathrm{~s}^{-1}\right.$ and $\left.\mathrm{A}_{11}=2.18 \times 10^{6} \mathrm{~s}^{-1}\right)$, the values of the electronic transition moment calculated from Eq. (1) are equal to $0.554 \mathrm{D}$ and $0.516 \mathrm{D}$ respectively for the (0-0) and (1-1) bands. For the $\mathrm{R}_{1}(6)$ transition at $29948.45 \mathrm{~cm}^{-1}(333.9 \mathrm{~nm})$, PGOPHER calculations return $A_{J^{\prime} J^{\prime \prime}}=1.375 \times 10^{6} \mathrm{~s}^{-1}$ and $f_{J^{\prime \prime} J^{\prime}}=$ $2.653 \times 10^{-3}$. The absorption line strength is equal to 3.992 , in good agreement with the value of 3.988 reported by Derzy et al. [7].

\section{LIF and CRDS measurements of NH in flames}

\subsection{Excitation LIF and CRDS absorption spectra}

Experimental spectra were measured in flame $\mathrm{CH} 4-\mathrm{N} 2 \mathrm{O}$ at the $\mathrm{NH}$ peak location $(\mathrm{HAB}=5.5 \mathrm{~mm})$, where the temperature was previously determined to be equal to $1790 \mathrm{~K}$ [9]. The absorption spectrum of the NH radical was recorded by using CRDS. The excitation LIF spectrum was also recorded in the linear regime $\left(8 \mu \mathrm{J} / \mathrm{cm}^{2} /\right.$ pulse $)$ with a collection spectral bandwidth of $9.0 \mathrm{~nm}$. Figure 1 presents the experimental spectra measured by CRDS and by LIF, compared to the absorption spectrum simulated with PGOPHER at $1790 \mathrm{~K}$ by applying a Voigt lineshape function with a Gaussian linewidth of 0.25 $\mathrm{cm}^{-1}$ and a Lorentzian linewidth of $0.15 \mathrm{~cm}^{-1}$. All spectra have been scaled with respect to the experimental absorption spectrum reported in losses per pass along the flame diameter. Spectra show three intense transitions which correspond to $R$ transitions in the 3 sub-bands $\left(R_{1}, R_{2}, R_{3}\right)$ of the lower state N" $=5$ in the (0-0) band. Two small transitions $\left(\mathrm{R}_{2}(9), \mathrm{R}_{1}(10)\right)$ in the (1-1) band are also observed. A fairly good agreement between the experimental intensities and the simulated intensities is found. However, the intensity of the two satellite transitions $\left(\mathrm{Q}_{32}(5), \mathrm{Q}_{21}(6)\right)$ in the $(0,0)$ band measured by LIF is higher than the simulated intensity while the absorption experimental spectrum is perfectly 
simulated. The simulated spectrum being an absorption spectrum, it does not correct for the fluorescence quantum yield. Therefore the disagreement observed for the two satellite lines indicates that their fluorescence quantum yield differs from the one of the main transitions.

More details concerning the dispersed fluorescence spectrum and the temporal fluorescence decays of NH in flames are given in the Supplementary Materials.

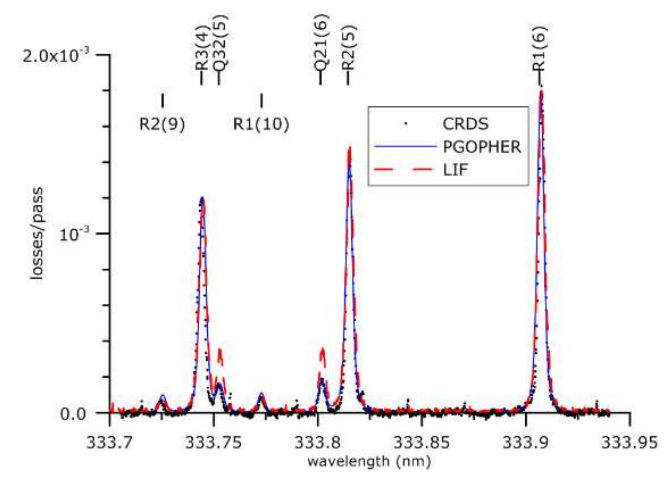

Fig. 1. NH absorption spectrum (symbols) and excitation LIF spectrum (dashed line) collected at $336 \mathrm{~nm}$ with a spectral bandwidth of $9 \mathrm{~nm}$, at $5.5 \mathrm{~mm}$ in flame CH4-N2O. Comparison with the simulated spectrum obtained with PGOPHER (solid line) at $\mathrm{T}=1790 \mathrm{~K}$ by using a Voigt lineshape function. Transitions in the (0-0) and (1-1) bands are indicated on the top.

\subsection{Experimental NH mole fraction profiles}

The NH mole fraction profiles were measured by using LIF and CRDS. The rotational population $\left(\mathrm{N}_{\mathrm{J}^{\prime}}\right)$ was probed at the well-resolved $\mathrm{R}_{1}(6)$ transition at $333.9 \mathrm{~nm}$ by LIF. The rotational distribution shows that the level J"=6 is one of the most populated levels in the temperature range (1000-1800 K), with a limited temperature sensitivity of the Boltzmann factor $\left(2 \times 10^{-5} \mathrm{~K}^{-1}\right)$. The axial $\mathrm{NH}$ relative concentration profiles as function of $\mathrm{HAB}$ were obtained by LIF that allows spatially resolved measurements. The relative concentration species profile in each flame was scaled at its peak value with respect to the one obtained in flame $\mathrm{CH} 4-\mathrm{N} 2 \mathrm{O}$ (calibration flame). This latter one was calibrated into absolute population by using CRDS. The integrated spectral absorptivity $A(\bar{v})$ (in $\mathrm{cm}^{-1}$ ) was determined according to Eq. (2) [17]:

$$
A(\bar{v})=\int L(\bar{v}) d \bar{v}=\left(\pi e^{2} / m_{e} c^{2}\right) f_{J^{\prime \prime} J^{\prime}} N_{J^{\prime \prime}} l_{s} \quad \text { Eq. (2) }
$$


where $m_{e} c^{2} / \pi e^{2}$ is equal to $1.13 \times 10^{12} \mathrm{~cm}^{-1}, l_{s}$ is the absorption length (in $\left.\mathrm{cm}\right) . L(\bar{v})$ represents the net losses per pass due to the absorption of the species $\left(\mathrm{N}_{J^{\prime \prime}}\right)$ as a function of the wavenumber $\bar{v}$. Conversion into absolute concentration $N_{t o t}$ was completed by dividing the rotational population by the Boltzmann factor $f_{\mathrm{B}}(\mathrm{J}$ ', $\mathrm{T})$, calculated by using the experimental temperature profiles previously obtained in $[10,14]$.

\subsubsection{Relative NH profiles by LIF}

In order to maximize the signal and prevent any perturbation from the excitation laser radiation, the fluorescence signal was collected along the Q- and P-branches, with a spectral bandwidth of $9 \mathrm{~nm}$ centered at $339 \mathrm{~nm}$. The fluorescence lifetime was found nearly identical in all flames and almost constant (80 ns) along the flames axis indicating that the $\mathrm{NH}$ quenching rates are similar. Thanks to this observation, the steadiness of the quenching rate allows to assume that the degree of saturation of the LIF signal is similar in each flame. Therefore, we have chosen to work in a partially saturated LIF regime (13-14 $\mu \mathrm{J} / \mathrm{cm}^{2} /$ pulse) in order to improve the signal-to-noise ratio. The off-resonance signal was found negligible.

The relative peak values of $\mathrm{N}_{\mathrm{J}}$, measured in all flames are reported Table 2. The relative standard deviation of the ratios between the flames is lower than $5 \%$. The temperature values previously measured in $[9,10,14]$ are also reported at the NH peak location.

Table 2. Relative rotational population $\left(\mathrm{N}_{\mathrm{J}}\right.$ ), absolute concentration $\left(\mathrm{N}_{\text {tot }}\right)$, mole fraction $\left(\chi_{\mathrm{NH}}\right)$ of $\mathrm{NH}$ measured at the peak location in all flames. Temperature at the peak was previously determined in $[9,10,14]$.

\begin{tabular}{|c|c|c|c|c|c|c|}
\hline flame & $\begin{array}{c}\mathrm{N}_{f^{\prime}}, \text { rel } \\
\text { LIF }\end{array}$ &  & $\begin{array}{c}\text { NH peak } \\
(\mathrm{mm})\end{array}$ & $\begin{array}{l}\mathrm{T}(\mathrm{K}) \text { at } \mathrm{NH} \\
\text { peak }\end{array}$ & $\begin{array}{c}\mathrm{N}_{\text {tot }} \\
\left(\text { molecule } / \mathrm{cm}^{3}\right)\end{array}$ & $\begin{array}{c}\chi_{\mathrm{NH}} \\
(\mathrm{ppb})\end{array}$ \\
\hline $\mathrm{CH} 4-\mathrm{N} 2 \mathrm{O}$ & 100 & $4.70 \times 10^{10}$ & 5.50 & 1790 & $1.33 \times 10^{12}$ & 6172 \\
\hline $\mathrm{C} 2 \mathrm{H} 2(125)$ & 3.66 & $1.72 \times 10^{9}$ & 2.75 & 1640 & $4.54 \times 10^{10}$ & 193 \\
\hline $\mathrm{C} 2 \mathrm{H} 2(100)$ & 1.43 & & 2.75 & 1565 & $1.72 \times 10^{10}$ & 70 \\
\hline $\mathrm{CH} 4(125)$ & 0.94 & & 9.00 & 1750 & $1.23 \times 10^{10}$ & 56 \\
\hline $\mathrm{CH} 4(100)$ & 0.29 & & 6.75 & 1770 & $3.90 \times 10^{9}$ & 18 \\
\hline
\end{tabular}

\subsubsection{Mole fraction profiles of NH by CRDS}

The NH net losses $L(\bar{v})$ were measured in flame CH4-N2O. The net losses profile is in agreement with the scaled LIF profile as shown in Fig. 2. The enlargement of the line-of-sight CRDS profile at high 
HAB can be due to a possible flame curvature as shown previously [22] although the flame was visually flat. Possible inhomogeneities at the flame edge are known to affect the axial mole fraction. In this work, the radial $\mathrm{NH}$ mole fraction profiles have not been measured. Therefore the NH mole fraction profiles are not corrected for the effective absorption pathlength which is assumed to be the flame diameter $\left(l_{s}=6 \mathrm{~cm}\right)$ in Eq. (2).



Fig. 2. $\mathrm{N}_{J}$, profiles (net losses/pass, $L(\bar{v})$ ) measured by using LIF and CRDS in flame CH4-N2O.

The NH mole fraction was measured by probing the $\mathrm{R}_{1}(6)$ transition at the $\mathrm{NH}$ peak location in flames $\mathrm{CH} 4-\mathrm{N} 2 \mathrm{O}$ and $\mathrm{C} 2 \mathrm{H} 2(125)$. The signal to noise ratio was around 3-4 only in the latter flame. From the integrated spectral absorptivity, $\mathrm{N}_{J}$, was determined to be equal to $4.70 \times 10^{10}$ molecule $\mathrm{cm}^{-3}$ in flame $\mathrm{CH} 4-\mathrm{N} 2 \mathrm{O}$ with a relative standard deviation of $2.5 \%$. The ratio of the rotational populations between this flame and flame $\mathrm{C} 2 \mathrm{H} 2(125)$ using CRDS was found in perfect agreement with the ratio of $\mathrm{N}_{J}$, measured by LIF (Table 2). Then, considering the temperature equal to $1790 \mathrm{~K}$ at the $\mathrm{NH}$ peak location in flame $\mathrm{CH} 4-\mathrm{N} 2 \mathrm{O}$, the $\mathrm{NH}$ peak mole fraction was calculated to be equal to $6.17 \mathrm{ppm}$.

After the calibration performed in flame $\mathrm{CH} 4-\mathrm{N} 2 \mathrm{O}$, the profiles of the relative rotational population were converted into mole fraction by considering the Boltzmann factor and the temperature profiles. Thanks to the combination of LIF and CRDS techniques, the NH profile in the stoichiometric flame could be measured with a peak mole fraction value as low as $18 \mathrm{ppb}$. The accuracy of the rotational absorption line strength was estimated to be $\pm 10 \%$, in agreement with the estimated error 
reported by [21]. Finally, the accuracy of the NH mole fraction determination was estimated to be $\pm 20 \%$, neglecting the possible spatial inhomogeneity of the NH distribution.

\section{Modeling and discussions}

Modeling was performed using either the GDFkin ${ }^{\circledR} 3.0$ model [12] for $\mathrm{CH}_{4}$ oxidation or the Lindstedt and Skevis model [13] for $\mathrm{C}_{2} \mathrm{H}_{2}$ oxidation (named LS hereafter). These models were completed with the NOMecha2.0 submechanism [10]. NOMecha2.0 was fully validated in low-pressure flames for the prompt-NO formation against a large experimental database gathering species such as NCN, NCO, $\mathrm{HCN}, \mathrm{CN}, \mathrm{CH}$ and $\mathrm{NO}$. NH was one of the missing intermediate species involved in the prompt-NO scheme. Calculations were done with the Chemkin/Premix-II package, using the experimental temperature profiles previously reported in $[10,14]$. The NH profiles were simulated in all flames. Figure 3 shows the comparison between the experimental and the simulated profiles in the methane flames. Although the predictions underestimate by about $30 \%$ the experimental $\mathrm{NH}$ peak values, the ability of NOMecha2.0 to predict intermediate species below only $60 \mathrm{ppb}$ is considered as good. This figure is complementary to those previously reported in [10].

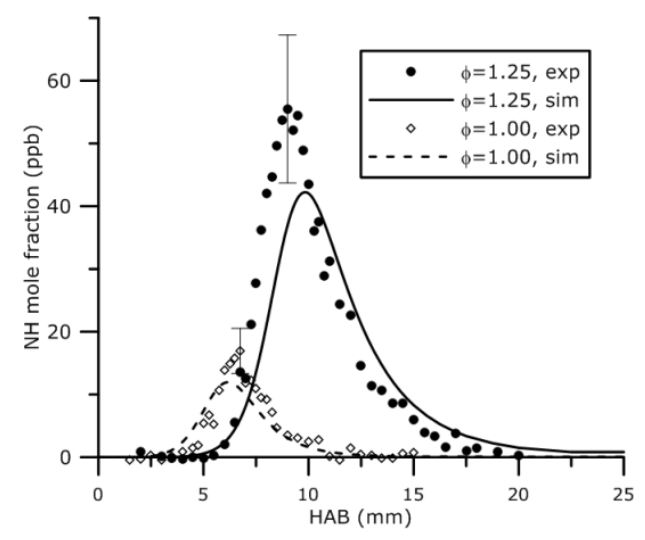

Fig. 3. Experimental $\mathrm{NH}$ mole fraction profiles in flames $\mathrm{CH}_{4}$ at $\phi=1.25$ and $\phi=1.0$. Comparison with simulated profiles obtained with NOMecha2.0 [10] associated to GDFkin ${ }^{\circledR} 3.0$ [12]. 
The acetylene oxidation mechanism proposed by Lindstedt and Skevis [13] was previously adopted to simulate prompt-NO and intermediate species in the acetylene flames as reported in $[10,14]$. This model allowed good predictions of the $\mathrm{CH}$ and $\mathrm{NCN}$ mole fraction profiles obtained in flames $\mathrm{C} 2 \mathrm{H} 2(100)$ and $\mathrm{C} 2 \mathrm{H} 2(125)$. However as shown in Fig. 4, the experimental NO mole fraction profiles were underestimated by the model by a factor of 1.2 and 1.6 in the rich and stoichiometric flames, respectively. No change of the mechanism was performed in [10] to improve the agreement between the experimental and the simulated profiles of NO. The NH mole fraction profiles simulated with the LS model underpredicted the experimental profiles with a factor of 5.2 and 3.7 in flames $\mathrm{C} 2 \mathrm{H} 2(100)$ and $\mathrm{C} 2 \mathrm{H} 2(125)$, respectively.

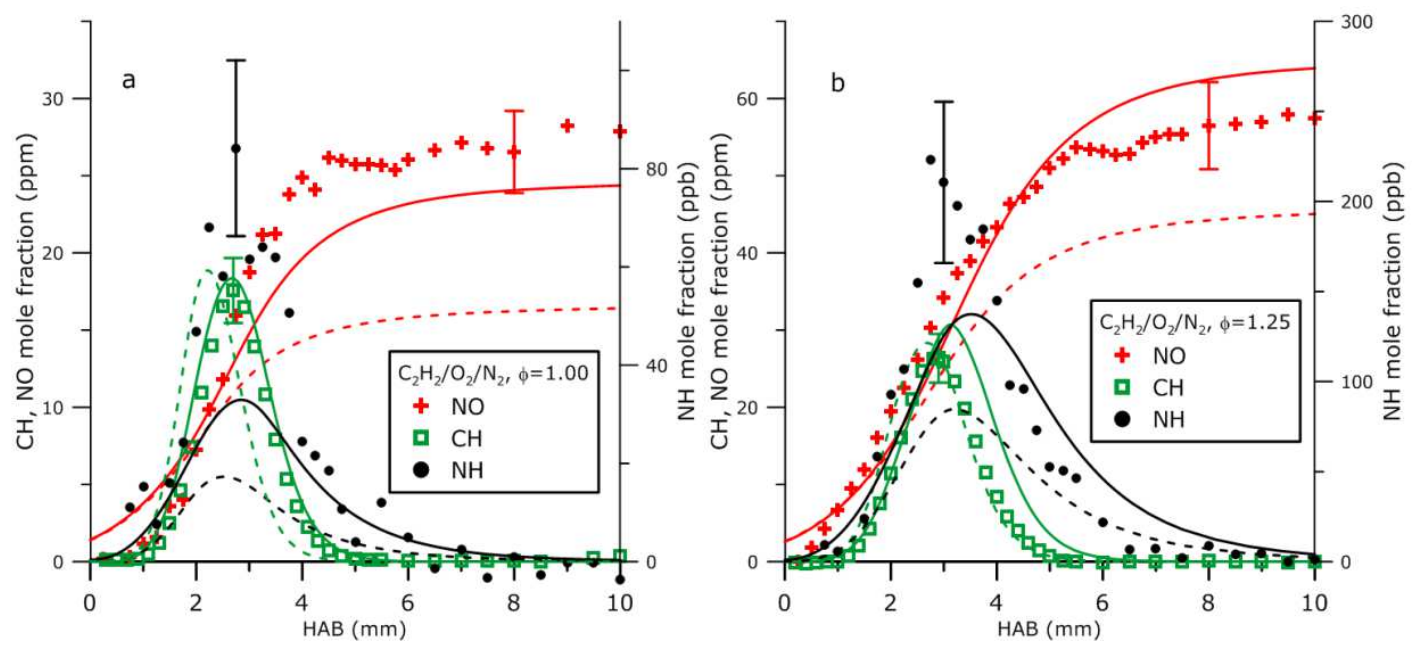

Fig. 4. $\mathrm{NH}$ mole fraction profiles in flames $\mathrm{C}_{2} \mathrm{H}_{2}$ (a) $\phi=1.25$ and (b) $\phi=1.0$. Comparison with the simulated profiles obtained with NOMecha2.0 model [10] associated to the revised LS model (solid lines) and the unmodified LS model [13] (dashed lines).

In order to explain why $\mathrm{NH}$ profiles are better predicted in the methane flames than in the acetylene flames, analyses of the reaction rate of production have been performed in both flames. $\mathrm{NH}$ species are consumed according to the reactions $\mathrm{NH}+\mathrm{H}=\mathrm{N}+\mathrm{H}_{2}$ and $\mathrm{NH}+\mathrm{O}=\mathrm{NO}+\mathrm{H}$. $\mathrm{NH}$ species are mostly formed according to three reactions (listed by order of importance): $\mathrm{NCO}+\mathrm{H}=\mathrm{NH}+\mathrm{CO}$, $\mathrm{NH}_{2}+\mathrm{H}=\mathrm{NH}+\mathrm{H}_{2}$ and $\mathrm{HCN}+\mathrm{O}=\mathrm{NH}+\mathrm{CO}$. The relative importance of the second reaction falls down in the acetylene flames contrary to what is observed in the methane flames. In both flames, $\mathrm{NH}_{2}$ species are mostly formed from the reaction $\mathrm{HNCO}+\mathrm{H}=\mathrm{NH}_{2}+\mathrm{CO}$ and consumed according to the reaction 
$\mathrm{NH}_{2}+\mathrm{H}=\mathrm{NH}+\mathrm{H}_{2}$ through the newly additional pathway $\mathrm{HCN} / \mathrm{HNC} / \mathrm{HNCO} / \mathrm{NH}_{2} / \mathrm{NH}$ as discussed in [10]. This sequence was mostly updated from [23] and [24]. The experimental HCN peak mole fraction values were satisfyingly predicted for all flames [10]. HNCO is formed from the reaction $\mathrm{HNC}+\mathrm{OH}=\mathrm{HNCO}+\mathrm{H}$ in both flames, but in the acetylene flames it is also formed through the reaction of isomerisation $\mathrm{HCNO}+\mathrm{H}=\mathrm{HNCO}+\mathrm{H}$. According to [25], $\mathrm{HCNO}$ is produced from the reactions $\mathrm{HCCO}+\mathrm{NO}=\mathrm{HCNO}+\mathrm{CO}$ and $\mathrm{CH}_{2}+\mathrm{NO}=\mathrm{HCNO}+\mathrm{H}$. In the methane flames, these two reactions are involved yielding a simulated peak mole fraction of HCCO around a few tens of ppm in the rich conditions. On the contrary, the first reaction is the only one involved in the HCCO formation with a simulated peak mole fraction around 10 times higher in the rich acetylene flame. As previously described in [14], $\mathrm{HCCO}$ is the first intermediate species of the acetylene oxidation, whereas $\mathrm{CH}_{3}$ is the first intermediate species of the methane oxidation. Indeed, in the acetylene flames, HCCO plays an important role due to the reaction $\mathrm{C}_{2} \mathrm{H}_{2}+\mathrm{O}=\mathrm{HCCO}+\mathrm{OH}$ [26]. The reactions $\mathrm{C}_{2} \mathrm{H}_{2}+\mathrm{O}$ and $\mathrm{HCCO}+\mathrm{O}_{2}$ are well-known to be very sensitive for modeling the acetylene/air laminar flame velocities as previously mentioned by Lindstedt and Skevis [13], and recently by Shen et al. [26].

In order to improve the agreement between the experimental and the simulated mole fraction profiles of $\mathrm{NH}$ in the acetylene flames, the rate constant values of the reactions $\mathrm{C}_{2} \mathrm{H}_{2}+\mathrm{O}$ and $\mathrm{HCCO}+\mathrm{O}_{2}$ have been modified in the LS model as listed in Table 3. These modifications increase the simulated peak mole fraction of $\mathrm{HCCO}$ by a factor of 2 , and the one of ${ }^{1} \mathrm{CH}_{2}$ by a factor 1.5 in flame $\mathrm{C} 2 \mathrm{H} 2(125)$. The modifications also yield an increase of the simulated $\mathrm{CH}$ peak mole fraction by a factor of 1.6. Indeed as shown in [14], $\mathrm{CH}$ radicals are formed through the sequence $\mathrm{HCCO} /{ }^{1} \mathrm{CH}_{2} /{ }^{3} \mathrm{CH}_{2} / \mathrm{CH}$ in the acetylene flame. In order to restrain the simulated $\mathrm{CH}$ mole fraction profiles (in agreement with the experimental profiles), the rate constant value of the reaction $\mathrm{CH}+\mathrm{H}_{2}={ }^{3} \mathrm{CH}_{2}+\mathrm{H}$ was modified according to [27]. The predictions of the species profiles previously considered to validate the original LS mechanism by [13] were not altered.

Table 3. Modified reaction rate constant values in the LS model [13]. $\mathrm{k}=\mathrm{AT} \mathrm{T}^{\mathrm{n}} \exp (-\mathrm{E} / \mathrm{RT})$, units in cal, mole, $\mathrm{cm}^{-3}$ and $\mathrm{K}$. 


\begin{tabular}{|c|c|c|c|c|}
\hline reaction & A & n & E & references \\
\hline $\mathrm{C}_{2} \mathrm{H}_{2}+\mathrm{O}={ }^{3} \mathrm{CH}_{2}+\mathrm{CO}$ & $4.7 \times 10^{7}$ & 1.4 & 2204 & Shen et al. $/ 5$ [26] \\
\hline $\mathrm{C}_{2} \mathrm{H}_{2}+\mathrm{O}=\mathrm{HCCO}+\mathrm{H}$ & $9.36 \times 10^{8}$ & 1.4 & 2204 & Shen et al. [26] \\
\hline $\mathrm{HCCO} \mathrm{O}_{2}=2 \mathrm{CO}+\mathrm{OH}$ & $1.91 \times 10^{11}$ & 0 & 1023 & Shen et al. [26] \\
\hline $\mathrm{HCCO}+\mathrm{O}_{2}=\mathrm{CO} \mathrm{CO}_{2}+\mathrm{CO}+\mathrm{H}$ & $4.78 \times 10^{12}$ & -0 & 1150 & Shen et al. [26] \\
\hline $\mathrm{CH}+\mathrm{H}_{2}={ }^{3} \mathrm{CH}_{2}+\mathrm{H}$ & $1.75 \times 10^{14}$ & 0 & 3320 & Baulch et al. [27] \\
\hline
\end{tabular}

Figure 4 shows the experimental and the simulated mole fraction profiles of $\mathrm{NH}, \mathrm{CH}$ and $\mathrm{NO}$ in the acetylene flames. For clarity, the species profiles simulated before and after the aforementioned kinetic modifications are presented here. Additionally, the species profiles of NCN and HCN are presented in the Supplementary Materials. These modifications allowed matching the simulated $\mathrm{CH}$ peak location with the experimental ones, especially in the flame $\mathrm{C} 2 \mathrm{H} 2(100)$. They also led to increase the simulated $\mathrm{NH}$ mole fraction profiles, but they still underestimate the experimental profiles by a factor of 2.7 and 1.6, respectively for flames $\mathrm{C} 2 \mathrm{H} 2(100)$ and $\mathrm{C} 2 \mathrm{H} 2(125)$. The predicted NO mole fractions in the burned gases were found in better agreement with the experimental values (within the experimental uncertainties) than previously shown in [10]. Globally, the simulated peak mole fractions of $\mathrm{CH}, \mathrm{NO}, \mathrm{NCN}, \mathrm{HCN}$ and $\mathrm{NH}$ have been increased (shown in the Supplementary Materials), yielding a better agreement with the experimental ones. However, the simulated HCN profiles are much larger than the experimental ones in the acetylene flames. This observation deserves further investigations.

\section{Conclusions}

The mole fraction profiles of $\mathrm{NH}$ have been measured in flames of $\mathrm{CH}_{4} / \mathrm{O}_{2} / \mathrm{N}_{2}$ or $\mathrm{C}_{2} \mathrm{H}_{2} / \mathrm{N}_{2} / \mathrm{O}_{2}$ stabilized at low pressure $(5.3 \mathrm{kPa})$. Measurements have been possible thanks to the combination of two laser-based spectroscopic techniques: LIF and CRDS. The LIF technique offers an excellent sensitivity and spatial resolution for measuring the relative species profiles in flames. We have estimated the limit of detection of $\mathrm{NH}$ of around $4.5 \times 10^{8}$ molecules $\mathrm{cm}^{-3}$, i.e. $2 \mathrm{ppb}$ at $1600 \mathrm{~K}$, while this limit was estimated to $0.4 \mathrm{ppm}$ in [8]. The high improvement of the detection limit is mainly due to the larger volume of collection. As the laser is not focused, the volume is enlarged in a plane parallel to the burner surface. The CRDS technique allows quantifying in absolute concentration but 
with a detection limit around $2 \times 10^{10}$ molecules $\mathrm{cm}^{-3}$, similarly to [7] . In the present work as in [7], the NH spatial distribution was assumed homogeneous along the absorption pathlength.

Modeling calculations were performed using the NOMecha2.0 submechanism recently developed for the prompt-NO formation [10]. Simulated NH profiles in the methane flames were found $30 \%$ lower than the experimental profiles. Modeling of the acetylene flames showed larger discrepancy with the experimental results. Acetylene oxidation yields intermediate species such as ketenyl radicals that play an important role in the prompt-NO formation through the formation of $\mathrm{HNCO}$ species. As previously indicated, the HNCO isomers are important for predicting NH species in the acetylene flames. The modification of five reaction rate constant values in the LS model [13] allowed retrieving a better agreement between the simulated and experimental species profiles $(\mathrm{CH}$, HCN, NCN, NH and NO). The refinement is clear for the NO simulated profiles which now agree well with the experimental profiles (within the experimental uncertainty). This was made possible thanks to the quantitative measurements of the trace radical $\mathrm{NH}$ in flames fueled either with methane or with acetylene. This confirms the robustness of the NO submechanism NOMecha2.0 [10] that has been completely reassessed in our laboratory thanks to the large experimental database of intermediate species involved in the prompt-NO formation.

\section{Acknowledgments}

This work is a contribution to the CPER research project CLIMIBIO. The authors thank the French Ministère de l'Enseignement Supérieur et de la Recherche, the Hauts-de-France Region and the European Funds for Regional Economical Development for their financial support to this project.

SMM.pdf file containing additional information concerning dispersed fluorescence spectra, temporal fluorescence decays, and species profiles (experimental and simulated obtained in the acetylene flames). 


\section{References}

[1] W.R. Anderson, L.J. Decker, A.J. Kotlar, Combust. Flame 48 (1982) 179-190.

[2] K.J. Rensberger, R.A. Copeland, M.L. Wise, D.R. Crosley, Symp. Int. Combust. 22 (1989) 1867-1875.

[3] M.C. Branch, M.E. Sadeqi, A.A. Alfarayedhi, P.J. Van Tiggelen, Combust. Flame 83 (1991) 228-239.

[4] S. Zabarnick, Combust. Sci. Technol. 83 (1992) 115-134.

[5] B.A. Williams, J.W. Fleming, Combust. Flame 98 (1994) 93-106.

[6] C. Brackmann, V.A. Alekseev, B. Zhou, E. Nordström, P.E. Bengtsson, Z. Li, M. Alden, A.A. Konnov, Combust. Flame 163 (2016) 370-381.

[7] I. Derzy, V.A. Lozovsky, N. Ditzian, I. Rahinov, S. Cheskis, Symp. Int. Combust. 28 (2000) 1741-1748.

[8] D.I. Shin, G. Peiter, T. Dreier, H.-R. Volpp, J. Wolfrum, Proc. Combust. Inst. 28 (2000) 319-325.

[9] N. Lamoureux, X. Mercier, J.-F. Pauwels, P. Desgroux, J. Phys. Chem. A 115 (2011) 5346-5353.

[10] N. Lamoureux, H. El Merhubi, L. Pillier, S. de Persis, P. Desgroux, Combust. Flame 163 (2016) 557-575.

[11] C.M. Western, J. Quant. Spectrosc. Radiat. Transf. 186 (2017) 221-242.

[12] A. El bakali, L. Pillier, P. Desgroux, B. Lefort, L. Gasnot, J.F. Pauwels, I. da Costa, Fuel 85 (2006) 896-909.

[13] R.P. Lindstedt, G. Skevis, Combust. Sci. Technol. 125 (1997) 73-137.

[14] N. Lamoureux, P. Desgroux, A. El Bakali, J.F. Pauwels, Combust. Flame 157 (2010) 1929-1941.

[15] N. Lamoureux, P. Desgroux, A. El Bakali, J.F. Pauwels, Combust. Flame 160 (2013) 745-746.

[16] X. Mercier, P. Jamette, J.F. Pauwels, P. Desgroux, Chem. Phys. Lett. 305 (1999) 334 342.

[17] X. Mercier, in: G. Berden (Ed.), Cavity Ring- Spectrosc. Tech. Appl., Wiley-Blackwell, 2009 , p. 344.

[18] R.S. Ram, P.F. Bernath, J. Mol. Spectrosc. 260 (2010) 115-119.

[19] J.S.A. Brooke, P.F. Bernath, C.M. Western, M.C. van Hemert, G.C. Groenenboom, J. Chem. Phys. 141 (2014) 054310.

[20] M. Larsson, Astron. Astrophys. 128 (1983) 291-298.

[21] A.M. Fernando, P.F. Bernath, J.N. Hodges, T. Masseron, J. Quant. Spectrosc. Radiat. Transf. 217 (2018) 29-34.

[22] J. Luque, J.B. Jeffries, G.P. Smith, D.R. Crosley, J.J. Scherer, Combust. Flame 126 (2001) 1725-1735.

[23] P. Dagaut, P. Glarborg, M.U. Alzueta, Prog. Energy Combust. Sci. 34 (2008) 1-46.

[24] Z. Tian, Y. Li, L. Zhang, P. Glarborg, F. Qi, Combust. Flame 156 (2009) 1413-1426.

[25] P. Dagaut, J. Luche, M. Cathonnet, Proc. Combust. Inst. 28 (2000) 2459-2465.

[26] X. Shen, X. Yang, J. Santner, J. Sun, Y. Ju, Proc. Combust. Inst. 35 (2015) 721-728.

[27] D.L. Baulch, C.T. Bowman, C.J. Cobos, R.A. Cox, T. Just, J.A. Kerr, M.J. Pilling, D. Stocker, J. Troe, W. Tsang, R.W. Walker, J. Warnatz, J. Phys. Chem. Ref. Data 34 (2005) 757-1397. 


\section{List of figure captions}

Fig. 1. NH absorption spectrum (symbols) and excitation LIF spectrum (dashed line) collected at 336 $\mathrm{nm}$ with a spectral bandwidth of $9 \mathrm{~nm}$, at $5.5 \mathrm{~mm}$ in flame CH4-N2O. Comparison with the simulated spectrum obtained with PGOPHER (solid line) at $\mathrm{T}=1790 \mathrm{~K}$ by using a Voigt lineshape function. Transitions in the (0-0) and (1-1) bands are indicated on the top.

Fig. 2. $\mathrm{N}_{J}$, profiles (net losses/pass, $L(\bar{v})$ ) measured by using LIF and CRDS in flame CH4-N2O.

Fig. 3. Experimental $\mathrm{NH}$ mole fraction profiles in flames $\mathrm{CH}_{4}$ at $\phi=1.25$ and $\phi=1.0$. Comparison with simulated profiles obtained with NOMecha2.0 [10] associated to GDFkin ${ }^{\circledR} 3.0$ [12].

Fig. 4. $\mathrm{NH}$ mole fraction profiles in flames $\mathrm{C}_{2} \mathrm{H}_{2}$ (a) $\phi=1.25$ and (b) $\phi=1.0$. Comparison with the simulated profiles obtained with NOMecha2.0 model [10] associated to the revised LS model (solid lines) and the unmodified LS model [13] (dashed lines). 